\title{
Cardiac Involvement in COVID-19-Assessment with Echocardiography and Cardiac Magnetic Resonance Imaging
}

\author{
Riccardo Cau ${ }^{1} \cdot$ Pierpaolo Bassareo $^{2} \cdot$ Luca Saba $^{1}$ (D)
}

Accepted: 28 May 2020 / Published online: 10 June 2020

(C) Springer Nature Switzerland AG 2020

\begin{abstract}
The outbreak of coronavirus disease 2019 (COVID-19), caused by severe acute respiratory syndrome coronavirus 2 (SARSCoV-2), started at the beginning of December 2019, in Wuhan, Hubei, China. Since then, the disease has been spreading quickly all over the world with dramatic consequences for global health. That is the reason why it was declared pandemic since March 11th, 2020. The clinical presentation of SARS-CoV-2 is quite variable. Respiratory symptoms dominate its clinical manifestations, but based on current observations, it can significantly affect the heart as well, thus leading to myocardial injury. Imaging plays a key role in the cardiovascular management of these patients, with the aim of improving their outcomes. This review article provides an overview as to strengths and weaknesses of cardiac magnetic resonance compared with echocardiography in the difficult management of these patients.
\end{abstract}

Keywords COVID-19 · SARS-COV-2 · Echocardiography · Cardiac magnetic resonance · Myocardial injury $\cdot$ Myocarditis · Imaging

$\begin{array}{ll}\begin{array}{l}\text { Abbreviations } \\ \text { SARS-CoV-2 }\end{array} & \begin{array}{l}\text { Severe acute respiratory syndrome } \\ \text { coronavirus 2 }\end{array} \\ \text { COVID-19 } & \begin{array}{l}\text { Coronavirus disease } 2019 \\ \text { Echocardiography }\end{array} \\ \text { ECHO } & \text { Cardiac magnetic resonance } \\ \text { C-MRI } & \text { Steady-state free precession } \\ \text { SSPF } & \text { Short tau inversion recovery } \\ \text { STIR } & \text { Late gadolinium enhancement } \\ \text { LGE } & \text { European Society of Cardiology } \\ \text { ESC } & \text { American College of Cardiology } \\ \text { ACC } & \text { American Heart Association } \\ \text { AHA } & \text { Appropriate use criteria } \\ \text { AUC } & \end{array}$

This article is part of the Topical Collection on Covid-19

Luca Saba

lucasaba@tiscali.it

1 Department of Radiology, Azienda Ospedaliero Universitaria (A.O.U.), di Cagliari - Polo di Monserrato s.s. 554, 09045 Monserrato, Cagliari, Italy

2 Mater Misericordiae University Hospital and Our Lady's Children's Hospital, University College of Dublin, Crumlin, Dublin, Republic of Ireland

\section{Background}

In December 2019, a series of unexplained pneumonia occurred in Wuhan, Hubei Province, China, and on January 9th, 2020, SARS-CoV-2 was officially identified as their underlying cause. Given the quick and steady viral spread, SARS-CoV-2 became such a big challenge for public health that COVID-19 was declared a pandemic by the World Health Organization on March 11th, 2020 [1, 2]. Several recent reports provide descriptions of the clinical signs associated with COVID-19. The disease ranges from mild infection to severe acute respiratory distress $[2,3]$. Wu et al. reported the largest case series to date of coronavirus disease and graded its clinical severity among 72,314 cases. Among them, $81.4 \%$ had just mild-to-moderate symptoms, while in $13.9 \%$ they were severe and in $4.7 \%$ critical [4].

A number of studies are now available in literature suggesting a correlation between COVID-19 and the cardiovascular system, in terms of increased mortality in subjects with a preexisting cardiovascular disease [5] as well as a direct myocardial injury caused by COVID-19 and testified by a significant increase in cardiac lesion biomarkers [3, 6-9]. The related studies are summarized in Table 1.

Cardiac damage can be determined not only by the virus, but also the drugs which are administered as a therapy against 


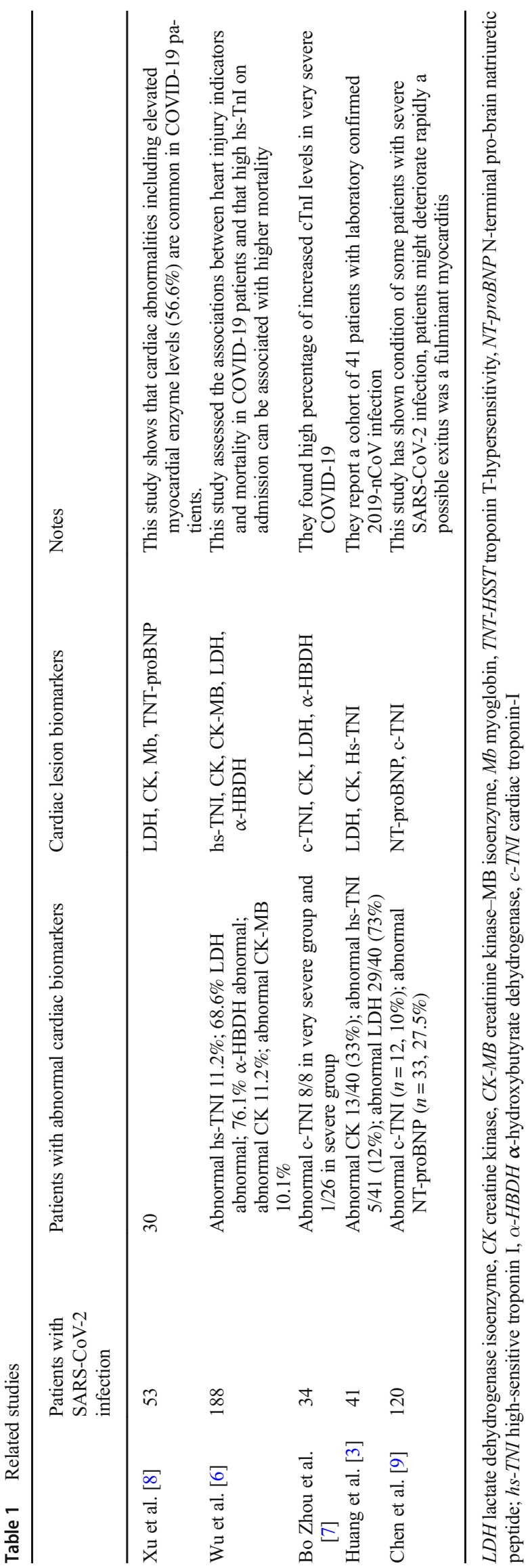

COVID-19, may have potentially harmful cardiovascular side effects and interactions with other medications [10, 11]. For this reason, they are under active investigation (see Table 2).

Imaging plays a pivotal role in the cardiovascular management of these patients, with the aim of improving their outcomes. This review article provides an overview as to strengths and weaknesses of cardiac magnetic resonance compared with echocardiography in the difficult management of these patients.

\section{Cardiovascular Involvement and the Role of Imaging}

A few studies hypothesized a potential role of this virus in inducing cardiac injury $[3,5-9,12]$. Although the specific underlying pathogenetic mechanism is still uncertain, several theories were proposed (see Table 3). They include an indirect cardiac damage (i.e. secondary to respiratory failure or to an exaggerated immune system response) as well as a direct effect owing to viral replication in the myocardium $[3,6,13,15]$. In this respect, it was recently suggested that COVID-19 as well as other coronaviruses may enter myocardial cells simply by binding type 2 ACE receptors on their surface [15]. Current literature reports suggest a link between preexisting cardiovascular disease and COVID-19 infection severity. In the already mentioned paper by Wu et al., cardiac involvement was associated with higher and earlier mortality [6]. Similar findings were reported in a meta-analysis recently published by $\mathrm{Li}$ et al. Patients with previous cardiovascular and/or metabolic diseases proved to have a greater risk of $2019-\mathrm{nCoV}$ infection and a poorer related prognosis. In addition, about $8 \%$ of COVID-19 patients suffered from acute cardiac injury [14].

The studies hypothesizing that SARS-CoV2 infection could lead to cardiovascular complications or exacerbate a preexisting cardiovascular disease $[4,5,12,16-18]$ are reported in Table 4.

Given the risk of virus-induced myocardial damage, cardiac complications, and drug-related cardiovascular side effects in the COVID-19 setting, cardiac imaging is likely be required in the care of patients with suspected or confirmed coronavirus infection (Fig. 1). It could be useful in diagnosing, monitoring, and perhaps predicting prognosis in those infected and with cardiac involvement. We will focus on the comparison between echocardiography and cardiac magnetic resonance imaging (c-MRI) regarding their own pros and cons in the cardiac management of patients with COVID-19.

\section{Echocardiography}

Echocardiography is considered an essential tool in evaluating cardiac structures and hemodynamics in many different 
Table 2 Active investigations on drugs administered as a therapy against COVID-19 that have potentially harmful cardiovascular side effects and interactions with other medications

\begin{tabular}{|c|c|c|c|}
\hline Therapy & Mechanism of action & $\mathrm{CV}$ drug class interactions & CV adverse effects \\
\hline $\begin{array}{l}\text { Kaletra (lopinavir and } \\
\text { ritonavir) }\end{array}$ & Synergistic action as protease inhibitors & $\begin{array}{l}\text { Antiplatelets, anticoagulants, statin, } \\
\text { antiarrhythmics }\end{array}$ & Altered cardiac conduction \\
\hline Hydroxychloroquine & $\begin{array}{l}\text { Alters endosomal } \mathrm{pH} \text { required for } \\
\text { virus/cell fusion }\end{array}$ & $\begin{array}{l}\text { Antiarrhythmics (prolongs the QT } \\
\text { interval) }\end{array}$ & $\begin{array}{l}\text { Direct cardiotoxicity, altered cardiac } \\
\text { conduction }\end{array}$ \\
\hline Methylprednisolone & $\begin{array}{l}\text { Alters gene expression to reduce } \\
\text { inflammation }\end{array}$ & Anticoagulants & $\begin{array}{l}\text { Fluid retention, electrolyte } \\
\text { disturbances, hypertension }\end{array}$ \\
\hline Azithromycin & $\begin{array}{l}\text { Macrolide antibiotics with } \\
\text { anti-inflammatory properties }\end{array}$ & Anticoagulants, antiarrhythmics & Altered cardiac conduction \\
\hline Ceftriaxone & Cephalosporins antibiotics & Antiarrhythmics, anticoagulants & Altered cardiac conduction \\
\hline
\end{tabular}

cardiac disorders $[19,20]$. It is one of the most powerful diagnostic and monitoring tools available in the management of patients with acute cardiovascular disease [21]. In those patients who are hemodynamically unstable, echocardiography allows to evaluate vital parameters such as global ejection fraction, wall motion abnormalities, cardiac output, and presence of tamponade. All these parameters can be done quickly and noninvasively at patient's bedside.

In the setting of COVID-19, echocardiography can be used to assess cardiovascular function in terms of chambers dimension and contractility. The possible presence of pericardial effusion can be detected and roughly quantified as well. It allows a diagnosis in case of COVID-19-related heart involvement, but also to periodically monitor patients, owing to their risk of worsening in a very short time [21].

Echocardiography is recommended as the first-line imaging test in many cardiac diseases [20].

In a position statement of the European Society of Cardiology (ESC) Working Group on Myocardial and Pericardial Diseases, it is clearly recommended that all patients with clinically suspected myocarditis should undergo an echocardiogram at disease presentation [22]. In addition, the American College of Cardiology (ACC) and American Heart Association (AHA) recommend the use of echocardiography in other scenarios, such as ischemic heart disease and in the setting of arrhythmias [20].

There is no doubt that echocardiography is a safe, versatile, and widely available technique. It allows to evaluate and quantify global and regional systolic function and monitor any possible changes in cardiac chambers size, wall thickness, ventricular function, and pericardial effusion. However, it also has its own weaknesses, such as inadequate myocardial tissue characterization and suboptimal field-of-view in the setting of poor acoustic windows. High interobserver variability is another common issue with echocardiography. Ventricular contractility can be evaluated more in depth by using postprocessing advanced echocardiography (strain, strain rate, speckle tracking), but it is a time-consuming technique, a significant expertise is needed, and it is likely to be useful just in determining prognosis and for research purposes.

One aspect to take into account when monitoring a patient with suspected or confirmed COVID-19 is the risk of exposure of healthcare workers. Wu et al. noticed that 1716 of the 44,672 (3.8\%) of infected individuals were healthcare workers [4]. In Italy, $20 \%$ of healthcare workers were infected, as reported by Remuzzi et al. [23]. All doctors and technicians involved in scanning these patients, either by c-MRI or echocardiography, should wear masks, plastic glasses, gloves, and scrubs. Related machines, probes, and rooms should be accurately sanitized after each examination. At the moment, there are no clear protocols, although some protective barriers and mandatory hand hygiene (every $2 \mathrm{~h}$ ) seem to be effective [24].

Hence, imaging should be performed according to local standards for the prevention of virus spread. Reports have suggested that transmission occurs most commonly via respiratory droplets and airborne transmission [25]. Echocardiography carries a higher risk of spreading SARS$\mathrm{CoV}-2$ during the examination compared with CMR [26].
Table 3 Theories on potential role of COVID-19 in inducing cardiac injury

\begin{tabular}{ll}
\hline Potential mechanism & \\
\hline Oudit et al. [13] & Viral infection directly causes damage to cardiomyocyte \\
Huang et al. [3] & Hypoxaemia \\
& Cytokine storm \\
& A potential role of activated T-helper-1 (Th1) cell responses \\
Li et al. [14] & Side effect of medication \\
& Anxiety with increase of catecholamines
\end{tabular}


Table 4 Studies hypothesizing that SARS-CoV2 infection could lead to cardiovascular complications or exacerbate a preexisting cardiovascular disease
Cardiovascular complications

Myocardial injuries [3, 6-9]

Acute myocarditis [12]

Fulminant myocarditis [9]

Cardiac Arrest [2]

Acute coronary syndrome [17]

Arrhythmia [2, 5]

\section{Cardiac MRI}

C-MRI is gaining a leading role in detecting and monitoring cardiovascular damage. It is an excellent tool for functional and morphological studies and allows also a reliable tissue characterization [27]. It is the non-invasive gold standard modality for quantification of left ventricle (LV) function, volumes, and mass [28]. For all these reasons, c-MRI scanning is entering the various guidelines as a strong recommendation [29].

By using a standard protocol based on functional sequences, such as cine white blood steady-state free precession (SSFP) on the short axis and long axes ( 2 chambers, 3 chambers, and 4 chambers) and tissue morphological and

characterization sequences such as T2 STIR (short tau inversion recovery) on both short and long axes, T1 pre- and postcontrast mappings, T2 mapping, and LGE (late gadolinium enhancement), c-MRI can provide a range of useful information for differential diagnosis of cardiovascular diseases [30-32]. In fact, it can be helpful in differentiating between ischemic and nonischemic acute myocardial injury, such as myocarditis [33]. Moreover, c-MRI may play an important role in diagnostic and therapeutic decision-making as well as in predicting prognosis [30]. LGE proved to have a prognostic value since patients with areas of necrosis and fibrosis are at increased risk of adverse cardiovascular events. In particular, the more extended fibrosis at LGE, the higher the risk of potentially life-threatening ventricular arrhythmias [34, 35]. On the contrary, LGE-negative patients have an excellent prognosis independently of their clinical symptoms [36]. Parametric mapping techniques such as T2 mapping, T1 mapping, and ECV could increase c-MRI diagnostic accuracy. Specifically, the T2 mapping technique can accurately and reliably detect areas of myocardial edema without the limitations of qualitative T2W imaging [37]. Again, native T1 is sensitive to intracellular and extracellular changes in free water content and its relaxation time increase during acute

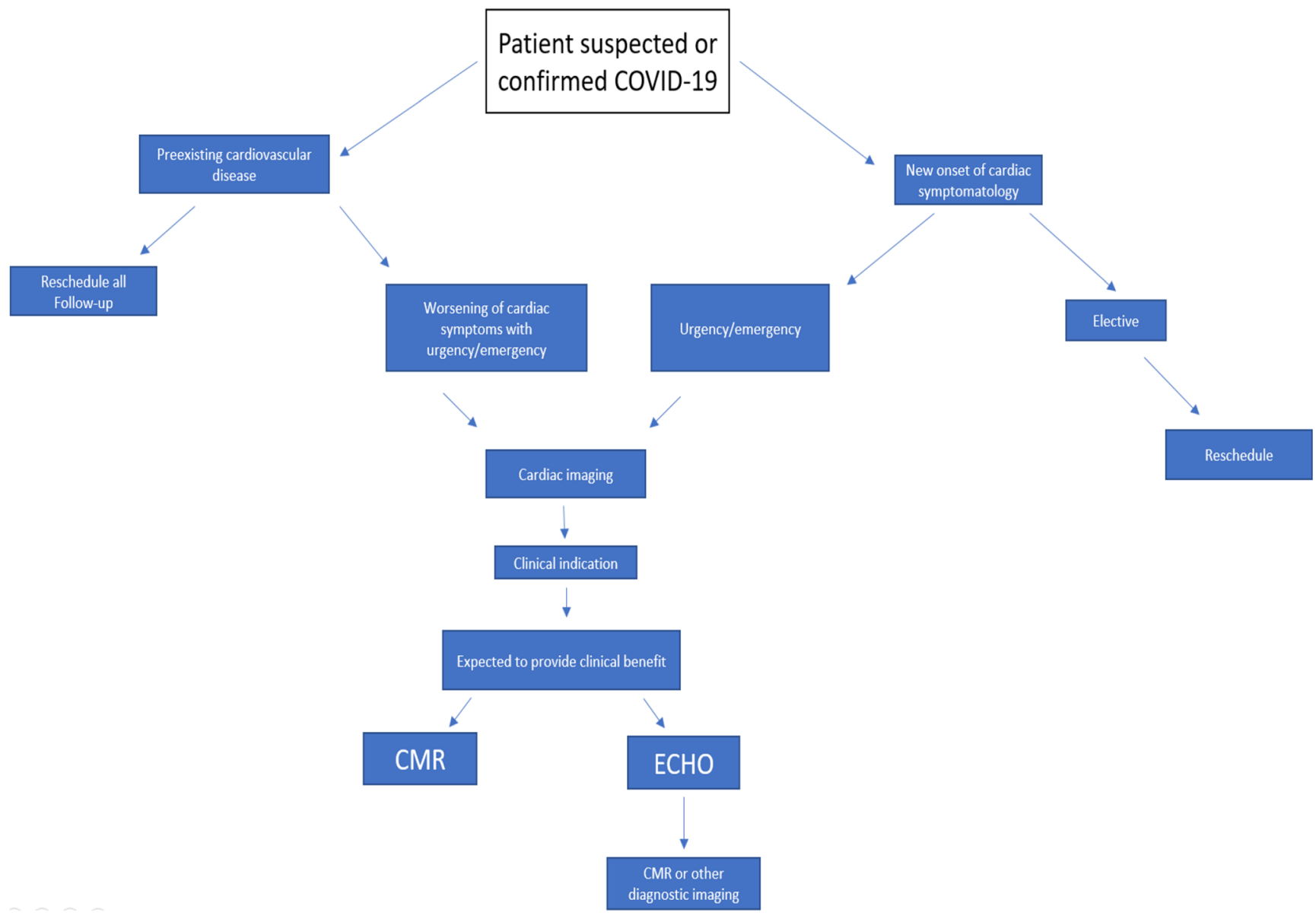

Fig. 1 Suggested algorithm in the cardiac management of patient suspected or confirmed COVID 
Table 5 Cardiac imaging modalities with their own pros and cons

Cardiac imaging modalities

\begin{tabular}{|c|c|c|}
\hline Imaging modalities & Strengths & Limitations \\
\hline Echocardiography & $\begin{array}{l}\text { Non-invasive } \\
\text { Fast } \\
\text { Safe } \\
\text { Versatile } \\
\text { Widely available technique } \\
\text { Useful in emergency } \\
\text { First-line in many cardiac disease } \\
\text { No radiation exposure or use of contrast }\end{array}$ & $\begin{array}{l}\text { Inadequate soft tissue characterization } \\
\text { Poor acoustic windows } \\
\text { Interobserver variability }\end{array}$ \\
\hline CMR & $\begin{array}{l}\text { Non-invasive } \\
\text { Tissue characterization } \\
\text { High spatial and temporal resolution } \\
\text { Excellent reproducibility } \\
\text { No radiation exposure } \\
\text { Prognostic value }\end{array}$ & $\begin{array}{l}\text { Low availability } \\
\text { Costs } \\
\text { Intrinsic or extrinsic factors of the patient (claustrophobia, metallic } \\
\text { implants, allergy, ability to hold breath and arrhythmia) } \\
\text { Long scan times } \\
\text { Use of contrast }\end{array}$ \\
\hline
\end{tabular}

inflammation, vasodilation, and hyperemia. Lastly, ECV is a marker of myocardial tissue remodeling and, compared with LGE that allow the detection of focal fibrosis [38], may assess diffuse fibrosis and inflammation [39].

Thereby c-MRI, in COVID-19 patients with suspected myocardial involvement, is the only noninvasive imaging modality that allows a tissue characterization in terms of assessing the possible presence and extent and prognosis (reversible/irreversible injury) of myocardial damage.

The use of c-MRI is currently limited by low availability, costs, being time-consuming, and patient's intrinsic or extrinsic factors (i.e. ability to hold breath, claustrophobia, metallic implants, allergy to contrast media, arrhythmia) [31]. The situation as it stands, doing a c-MRI scan in a COVID-19 patient who is ventilated and often intubated may be troublesome. A possible solution to reduce the examination time is to use a modern magnet with a reduced time of scanning. Applying a specific short protocol (for example with the only acquisition of SSFP and T2 mapping sequences to assess cardiac chamber volumes, global and regional kinesis, and the presence of edema) may be very useful as well. As soon as patients are discharged from intensive care unit to sub-intensive ward, a complete protocol including LGE for fibrosis (permanent damage) is likely to be feasible. Lastly, given the severity of the illness and the primary aim of urgently managing infection and respiratory failure and also the risk of exposure of healthcare personnel, a significant issue is represented by the risk of spreading the infection when moving a patient through the hospital to the c-MRI scanner room. The latter needs to be accurately disinfected after the exam.

\section{Conclusion}

In the setting of COVID 19, a significant number of patients have a clear concomitant cardiac involvement [14]. Although the specific underlying mechanism of myocardial injury during coronavirus infection is still under debate, heart entanglement is significantly associated with fatal outcomes in COVID-19 infection. Cardiac imaging modalities such as echocardiography and c-MRI, with their own pros and cons (Table 5), are both potentially useful in helping to make an early diagnosis and thus ultimately improve outcome. While echocardiography allows a prompt diagnosis and is more handy for patients' tight monitoring at bedside, c-MRI appears very promising in refining diagnosis (ideally by using a short protocol in the acute COVID-19 phase and the usual complete protocol at the time of discharging patients). Overall, echocardiography and c-MRI can be considered complementary in patients suspicious of cardiac involvement of COVID-19 and should be routinely used.

\section{Compliance with Ethical Standards}

Ethical Statement The authors of this manuscript declare no relationships with any companies, whose products or services may be related to the subject matter of the article. Institutional Review Board approval and written informed consent was not required because this is a retrospective study.

\section{References}

1. Lu H, Stratton CW, Tang YW. Outbreak of pneumonia of unknown etiology in Wuhan, China: the mystery and the miracle. J Med Virol. 2020;92(4):401-2. https://doi.org/10.1002/jmv.25678.

2. Wang D, Hu B, Hu C, Zhu F, Liu X, Zhang J, et al. Clinical characteristics of 138 hospitalized patients with 2019 novel coronavirus-infected pneumonia in Wuhan, China [published online ahead of print, $2020 \mathrm{Feb}$ 7]. JAMA. 2020;323(11):1061-9. https://doi.org/10.1001/jama.2020.1585.

3. Huang C, Wang Y, Li X, Ren L, Zhao J, Hu Y, et al. Clinical features of patients infected with 2019 novel coronavirus in Wuhan, China [published correction appears in Lancet. 2020 
Jan 30;]. Lancet. 2020;395(10223):497-506. https://doi.org/10. 1016/S0140-6736(20)30183-5.

4. Wu Z, McGoogan JM. Characteristics of and important lessons from the coronavirus disease 2019 (COVID-19) outbreak in China: summary of a report of 72314 cases from the Chinese Center for Disease Control and Prevention. JAMA. 2020;323(13): 1239-42. https://doi.org/10.1001/jama.2020.2648.

5. Guo T, Fan Y, Chen M, et al. Cardiovascular implications of fatal outcomes of patients with coronavirus disease 2019 (COVID-19) [published online ahead of print, 2020 Mar 27]. JAMA Cardiol. 2020:e201017. https://doi.org/10.1001/jamacardio.2020.1017.

6. Wu C, Hu X, Song J, Du C, Xu J, Yang D, et al. Heart injury signs are associated with higher and earlier mortality in coronavirus disease 2019(COVID19). medRxiv:2020.02.26.20028589. https://doi. org/10.1101/2020.02.26.20028589.

7. He XW, Lai JS, Cheng J, et al. Zhonghua Xin Xue Guan Bing Za Zhi. 2020;48(0):E011. https://doi.org/10.3760/cma.j.cn11214820200228-00137.

8. Xu H, Hou K, Xu H, Li Z, Chen H, Zhang N, et al. Acute myocardial injury of patients with coronavirus disease 2019. medRxiv: 2020.03.05.20031591. https://doi.org/10.1101/2020.03.05. 20031591.

9. Chen C, Zhou Y, Wang DW. SARS-CoV-2: a potential novel etiology of fulminant myocarditis. Herz. 2020;45(3):230-2. https://doi. org/10.1007/s00059-020-04909-z.

10. (2013) KALETRA(R) oral film coated tablets, oral solution, lopinavir ritonavir oral film coated tablets, oral solution. Product Insert. AbbVie Inc. (per FDA), North Chicago

11. Page RL 2nd, O'Bryant CL, Cheng D, et al. Drugs that may cause or exacerbate heart failure: a scientific statement from the American Heart Association [published correction appears in Circulation. 2016 Sep 20;134(12):e261]. Circulation. 2016;134(6):e32-69. https://doi.org/10.1161/CIR.0000000000000426.

12. Inciardi RM, Lupi L, Zaccone G, et al. Cardiac involvement in a patient with coronavirus disease 2019 (COVID-19) [published online ahead of print, 2020 Mar 27]. JAMA Cardiol. 2020. https://doi. org/10.1001/jamacardio.2020.1096, https://doi.org/10.1001/ jamacardio.2020.1096.

13. Oudit GY, Kassiri Z, Jiang C, Liu PP, Poutanen SM, Penninger JM, et al. SARS-coronavirus modulation of myocardial ACE2 expression and inflammation in patients with SARS. Eur J Clin Investig. 2009;39(7):618-25. https://doi.org/10.1111/j.1365-2362.2009. 02153.x.

14. Li B, Yang J, Zhao F, Zhi L, Wang X, Liu L, et al. Prevalence and impact of cardiovascular metabolic diseases on COVID-19 in China. Clin Res Cardiol. 2020;109(5):531-8. https://doi.org/10. 1007/s00392-020-01626-9.

15. Zheng YY, Ma YT, Zhang JY, Xie X. COVID-19 and the cardiovascular system. Nat Rev Cardiol. 2020;17(5):259-60. https://doi. org/10.1038/s41569-020-0360-5.

16. Zhou F, Yu T, Du R, et al. Clinical course and risk factors for mortality of adult inpatients with COVID-19 in Wuhan, China: a retrospective cohort study [published correction appears in Lancet. 2020 Mar 28;395(10229):1038] [published correction appears in Lancet. 2020 Mar 28;395(10229):1038]. Lancet. 2020;395(10229):1054-62. https://doi.org/10.1016/S01406736(20)30566-3.

17. Madjid M, Miller CC, Zarubaev VV, Marinich IG, Kiselev OI, Lobzin YV, et al. Influenza epidemics and acute respiratory disease activity are associated with a surge in autopsy-confirmed coronary heart disease death: results from 8 years of autopsies in 34,892 subjects. Eur Heart J. 2007;28(10):1205-10. https://doi.org/10. 1093/eurheartj/ehm035.

18. Buzon J, Roignot O, Lemoine S, Perez P, Kimmoun A, Levy B, et al. Takotsubo cardiomyopathy triggered by influenza A virus.
Intern Med. 2015;54(16):2017-9. https://doi.org/10.2169/ internalmedicine.54.3606.

19. Pepi M, Evangelista A, Nihoyannopoulos P, Flachskampf FA, Athanassopoulos G, Colonna P, et al. Recommendations for echocardiography use in the diagnosis and management of cardiac sources of embolism: European Association of Echocardiography (EAE) (a registered branch of the ESC). Eur J Echocardiogr. 2010;11(6):461-76. https://doi.org/10.1093/ejechocard/jeq045.

20. Douglas PS, Khandheria B, Stainback RF, et al. ACCF/ASE/ ACEP/ASNC/SCAI/SCCT/SCMR 2007 appropriateness criteria for transthoracic and transesophageal echocardiography: a report of the American College of Cardiology Foundation Quality Strategic Directions Committee Appropriateness Criteria Working Group, American Society of Echocardiography, American College of Emergency Physicians, American Society of Nuclear Cardiology, Society for Cardiovascular Angiography and Interventions, Society of Cardiovascular Computed Tomography, and the Society for Cardiovascular Magnetic Resonance endorsed by the American College of Chest Physicians and the Society of Critical Care Medicine. J Am Coll Cardiol. 2007;50(2):187-204. https://doi.org/10.1016/j.jacc.2007.05.003.

21. Lancellotti P, Price S, Edvardsen T, Cosyns B, Neskovic AN, Dulgheru R, et al. The use of echocardiography in acute cardiovascular care: recommendations of the European Association of Cardiovascular Imaging and the Acute Cardiovascular Care Association. Eur Heart J Acute Cardiovasc Care. 2015;4(1):3-5. https://doi.org/10.1177/2048872614568073.

22. Caforio AL, Pankuweit S, Arbustini E, et al. Current state of knowledge on aetiology, diagnosis, management, and therapy of myocarditis: a position statement of the European Society of Cardiology Working Group on Myocardial and Pericardial Diseases. Eur Heart J. 2013;34(33):2636-2648d. doi:https://doi.org/10.1093/eurheartj/ eht210.

23. Remuzzi A, Remuzzi G. COVID-19 and Italy: what next? Lancet. 2020;395(10231):1225-8. https://doi.org/10.1016/S0140-6736(20) 30627-9.

24. Klompas M, Morris CA, Sinclair J, Pearson M, Shenoy ES. Universal masking in hospitals in the Covid-19 era [published online ahead of print, 2020 Apr 1]. N Engl J Med. 2020. https://doi. org/10.1056/NEJMp2006372.

25. Modes of transmission of virus causing COVID-19: implications for IPC precaution recommendations. WHO https://www.who.int/ publications-detail/modes-of-transmission-of-virus-causing-covid19-implications-for-ipc-precaution-recommendations 29 March 2020.

26. Kirkpatrick JN, Mitchell C, Taub C, Kort S, Hung J, Swaminathan M. ASE statement on protection of patients and echocardiography service providers during the 2019 novel coronavirus outbreak [published online ahead of print, 2020 Apr 6]. J Am Coll Cardiol. 2020: S0735-1097(20)34815-4. https://doi.org/10.1016/j.jacc.2020.04. 002 .

27. von Knobelsdorff-Brenkenhoff F, Schulz-Menger J. Role of cardiovascular magnetic resonance in the guidelines of the European Society of Cardiology. J Cardiovasc Magn Reson. 2016;18:6. https://doi.org/10.1186/s12968-016-0225-6.

28. Bellenger NG, Burgess MI, Ray SG, Lahiri A, Coats AJ, Cleland JG, et al. Comparison of left ventricular ejection fraction and volumes in heart failure by echocardiography, radionuclide ventriculography and cardiovascular magnetic resonance; are they interchangeable? Eur Heart J. 2000;21(16):1387-96. https://doi.org/10. 1053/euhj.2000.2011.

29. Zamorano JL, Lancellotti P, Rodriguez Muñoz D, Aboyans V, Asteggiano R, Galderisi M, et al. 2016 ESC Position Paper on cancer treatments and cardiovascular toxicity developed under the auspices of the ESC Committee for Practice Guidelines: The Task Force for cancer treatments and cardiovascular toxicity of the 
European Society of Cardiology (ESC) [published correction appears in Eur Heart J. 2016 Dec 24;]. Eur Heart J. 2016;37(36): 2768-801. https://doi.org/10.1093/eurheartj/ehw211.

30. Salerno M, Kramer CM. Advances in parametric mapping with CMR imaging [published correction appears in JACC Cardiovasc Imaging. 2013 Aug;6(8):929-30]. JACC Cardiovasc Imaging. 2013;6(7):806-22. https://doi.org/10.1016/j.jcmg.2013.05.005.

31. Saeed M, Van TA, Krug R, Hetts SW, Wilson MW. Cardiac MR imaging: current status and future direction. Cardiovasc Diagn Ther. 2015;5(4):290-310. https://doi.org/10.3978/j.issn.22233652.2015.06.07.

32. American College of Cardiology Foundation Task Force on Expert Consensus Documents, Hundley WG, Bluemke DA, et al. ACCF/ACR/AHA/NASCI/SCMR 2010 expert consensus document on cardiovascular magnetic resonance: a report of the American College of Cardiology Foundation Task Force on Expert Consensus Documents. J Am Coll Cardiol. 2010;55(23): 2614-62. https://doi.org/10.1016/j.jacc.2009.11.011.

33. Kramer CM, Barkhausen J, Flamm SD, Kim RJ, Nagel E, Society for Cardiovascular Magnetic Resonance Board of Trustees Task Force on Standardized Protocols. Standardized cardiovascular magnetic resonance (CMR) protocols 2013 update. J Cardiovasc Magn Reson. 2013;15(1):91. https://doi.org/10.1186/1532-429X-15-91.

34. Grün S, Schumm J, Greulich S, Wagner A, Schneider S, Bruder O, et al. Long-term follow-up of biopsy-proven viral myocarditis: predictors of mortality and incomplete recovery. J Am Coll Cardiol. 2012;59(18):1604-15. https://doi.org/10.1016/j.jacc.2012.01.007.

35. Becker MAJ, Cornel JH, van de Ven PM, van Rossum AC, Allaart $\mathrm{CP}$, Germans T. The prognostic value of late gadolinium-enhanced cardiac magnetic resonance imaging in nonischemic dilated cardiomyopathy: a review and meta-analysis. JACC Cardiovasc Imaging. 2018;11(9):1274-84. https://doi.org/10.1016/j.jcmg.2018.03.006.

36. Schumm J, Greulich S, Wagner A, et al. Cardiovascular magnetic resonance risk stratification in patients with clinically suspected myocarditis. J Cardiovasc Magn Reson. 2014;16(1):14. https:// doi.org/10.1186/1532-429X-16-14.

37. Mavrogeni S, Apostolou D, Argyriou P, Velitsista S, Papa L, Efentakis S, et al. T1 and T2 mapping in cardiology: "mapping the obscure object of desire". Cardiology. 2017;138(4):207-17. https://doi.org/10.1159/000478901.

38. Kim RJ, Albert TS, Wible JH, Elliott MD, Allen JC, Lee JC, Parker M, Napoli A, Judd RM; Gadoversetamide Myocardial Infarction Imaging Investigators. Performance of delayed-enhancement magnetic resonance imaging with gadoversetamide contrast for the detection and assessment of myocardial infarction: an international, multicenter, double-blinded, randomized trial. Circulation. 2008;117(5):629-637. doi: https://doi.org/10.1161/ CIRCULATIONAHA.107.723262

39. Ferreira VM, Schulz-Menger J, Holmvang G, Kramer CM, Carbone I, Sechtem U, et al. Cardiovascular magnetic resonance in nonischemic myocardial inflammation: expert recommendations. J Am Coll Cardiol. 2018;72(24):3158-76. https://doi.org/ 10.1016/j.jacc.2018.09.072.

Publisher's Note Springer Nature remains neutral with regard to jurisdictional claims in published maps and institutional affiliations. 